\title{
Momentum: An Economic View
}

\author{
Wilhelm Berghorn ${ }^{1} \&$ Sascha Otto ${ }^{2}$ \\ ${ }^{1}$ Mandelbrot Quantitative Research UG, Helmut-Lederer-Straße 19, 91056 Erlangen, Germany \\ ${ }^{2}$ Achterdiek 53b, 28359 Bremen, Germany \\ Correspondence: Dr. Wilhelm Berghorn, Mandelbrot Quantitative Research UG, Helmut-Lederer-Straße 19, 91056 \\ Erlangen, Germany. Tel: 49-9131-930-3725.
}

Received: June 12, 2017

Accepted: June 29, 2017

Online Published: July 7, 2017

doi:10.5430/ijfr.v8n3p142

URL: https://doi.org/10.5430/ijfr.v8n3p142

\begin{abstract}
Momentum strategies have widely been recognized in the literature for several markets, asset classes and time horizons. However, these strategies face a major objection as they significantly violate even the weak form of the efficient market hypothesis. Recently, it has been shown that, from a mathematical perspective, the inner dynamics of asset prices are better described by the Mandelbrot Market Model. This model uses fractal trends observed in real stock data, and the mathematical characteristics measured and used in the model show that trends in this fractal setup explain momentum. A central question attached to this mathematical analysis is why these long trends exist, economically. Although it has been documented well in the literature that investors are not rational and are prone to several biases, we show in this work by example that momentum strategies leverage fundamental, company-specific improvements of the business condition, capturing the value generation process. Consequently, this work supports the mathematical claims made previously: There are no efficient markets as investors constantly fail to anticipate available information.
\end{abstract}

Keywords: momentum effect, efficient market theory

\section{Introduction}

Since Jegadeesh (1993), momentum strategies have been documented for several markets (e.g. in Fama (2012)), across several asset classes Moskowitz (2010), Asness (2013) and several different time horizons Asness (2014). These findings provide empirical evidence of the invalidity of the efficient market hypothesis postulated by Fama (1970). Simple management rules allow the creation of portfolios with "abnormal" returns. These returns are not represented by a quantifiable additional risk, violating a core belief in finance, that higher returns compensate for higher risk (e.g., refer to Markowitz (1952), Lintner (1965), Sharpe (1964)). In this context, we must also reference the work of Choi (2014), who theoretically embeds dividend momentum into this classical framework.

Recently, we were able to show in Berghorn (2015-I) and Berghorn (2015-II) that the exploitation of trends in price data is at the core of these strategies. These price series trends led to the definition of the so-called Mandelbrot Market Model, since it implements a vision of Benoît Mandelbrot (Berghorn (2015-II)). From a mathematical standpoint, this model supports the empirical evidence for the existence of momentum strategies. At the same time it enables the modeling of fractal markets, which are turbulent in the sense of inhibiting higher risks. These results along with many other results published earlier, e.g., Mandelbrot (1968), Lo (1998) - suggest that there are no efficient markets because asset prices are not independent from historic information. In particular, the results in Berghorn (2015-II) show multi scale dependence econometrically. We are even unable to claim that there is only a long-term dependence because this effect appears in fine detailed structures during econometric analysis. (Note 1)

At the same time, important work from Shiller (2003), Kahneman (1979), and Tversky (1992) shows that a "rational investor" is unlikely to exist because markets are more volatile than quantitative models would allow and because of human biases when faced with uncertainty. However, momentum strategies are often considered to exploit these investor imperfections, e.g., Antoniou (2013).

In this study, we will present an economic view of momentum strategies. In particular, we will analyze a classic long-only momentum strategy used before in Berghorn (2015-I) and Berghorn (2015-II). We will analyze the formation period as well as the longest held positions in these strategies and more elaborately document the economic effects underlying momentum. In essence, these experiments show that momentum strategies mainly 
invest in portfolios of assets in which company-specific situations are improving. As these companies improve their business condition, the valuation increases. These "deterministic" and economically driven effects result in successively higher price evaluations of assets. This supports the findings of other authors that investors do not anticipate these effects in the way that efficient markets would.

\subsection{Classical Momentum and Contrarian Revisited}

In this section, we revisit the main results of Berghorn (2015-I). We use a classical long-only momentum strategy for the subsequent experiments. Based on a market's assets, the following strategy is executed monthly:

1. Calculate the historical 1-year performance of each individual asset in a market.

2. Rank the assets according to their performance from high (performance) to low.

3. Switch/rebalance the portfolio to the 10th decile of the best performing assets.

4. Subtract a transaction fee of $0.1 \%$ of the portfolio volume.

Additionally, we will compare this strategy with a contrarian strategy in which we collect the worst performers (lower 10th decile) in step 3 above.

\subsection{Market Data}

As in Berghorn (2015-I), we use the Prime-Standard market of the regulated Frankfurter Wertpapierbörse in Germany because this segment has the highest transparency rules. This market is also a prerequisite for companies listed in major market indices such as DAX (major 30 companies in Germany), MDAX (mid-cap segment), TecDAX (technology segment) and SDAX (small cap segment). For our analysis, we use the assets listed in these indexes during February 2015. We use the average price index as a market proxy. Dividend payments are not modeled in the following simulations, although they provide a significant contribution to major indices such as DAX and MDAX. Additionally, we do not correct for delisted companies (survivorship bias) because these have an adverse effect on performance calculations (e.g., see Berghorn (2015-I)). Price data is provided by Lenz und Partner AG, a subsidiary of the VWD group. This data source also includes dividend payment information. The economic data about the balance sheets of these companies are provided by Finance Base AG, Munich, Germany.

\subsection{Performance Characteristics - Momentum and Contrarian}

As is widely documented in the literature, the contrarian portfolio (lower 10th decile) significantly underperforms the classic momentum strategy (upper 10th decile). This is verified in Table 1, in which 31 assets make up the 10\% decile target portfolio (the market contains 310 assets). These target portfolios are compared to the market proxy using a price average based on all assets in that segment.

As discussed before in Berghorn (2015-I), the classic momentum strategy (long-only) significantly outperforms the market proxy by approximately $18 \%$ p.a. This significant excess return is not explained by a quantifiable additional risk. Volatility is slightly higher compared to the market proxy and the maximal drawdown is even lower compared with the market. For the sake of completeness, we plot the associated cumulative return graph for this strategy in Appendix 2.

As explored in the associated literature, the contrarian strategy significantly underperforms compared to the market. Over the period 2004-2011 analyzed in this work, the cumulative return is negative. The excess return is roughly $-9 \%$ p.a. This underperformance is accompanied with a higher volatility of approximately $25 \%$ p.a. as well as a higher maximal drawdown of approximately $-74 \%$. As seen in Appendix 3, there is a fast recovery period after the financial crisis 2008/2009. This effect contributes to "momentum crashes," originally documented by Daniel (2011), who used a long-short portfolio containing the top 10th decile on the long side and the bottom 10th decile on the short side. During momentum crashes the worst performers recover much faster than the winner portfolio. 
Table 1. Classic vs. Contrarian (Long-Only) Momentum Strategies

\begin{tabular}{|c|c|c|c|}
\hline \multirow[b]{2}{*}{2004 - 2014 (11 Years) } & \multirow[b]{2}{*}{ Market Proxy } & \multicolumn{2}{|c|}{ Long Only } \\
\hline & & $\begin{array}{c}\text { Classic } \\
\text { Momentum }\end{array}$ & $\begin{array}{l}\text { Contrarian } \\
\text { Momentum }\end{array}$ \\
\hline Characteristic & Averaged Price & $\begin{array}{c}\text { Upper 10\% } \\
\text { Decile }\end{array}$ & $\begin{array}{c}\text { Lower 10\% } \\
\text { Decile }\end{array}$ \\
\hline Return (\%) & $75,75 \%$ & $891,31 \%$ & $-35,43 \%$ \\
\hline Return (\% p.a.) & $5,26 \%$ & $23,19 \%$ & $-3,90 \%$ \\
\hline Excess Return (\%) & & $815,56 \%$ & $-111,19 \%$ \\
\hline Excess Return (\% p.a.) & & $17,93 \%$ & $-9,16 \%$ \\
\hline Volatility (\% p.a.) & $17,92 \%$ & $20,78 \%$ & $24,87 \%$ \\
\hline Daily Drift (\%) & $0,02 \%$ & $0,08 \%$ & $-0,02 \%$ \\
\hline Daily Volatility (\%) & $1,11 \%$ & $1,29 \%$ & $1,54 \%$ \\
\hline Risk Adjusted Return & 0,0177 & 0,0622 & $-0,0099$ \\
\hline Maximal Drawdown (\%) & $-64,48 \%$ & $-49,03 \%$ & $-74,09 \%$ \\
\hline Alpha & & $0,0615 \%$ & $-0,0331 \%$ \\
\hline Beta & & 0,9404 & 0,9094 \\
\hline Std.Dev. Alpha & & $0,0141 \%$ & $0,0217 \%$ \\
\hline Std.Dev. Beta & & 0,0127 & 0,0196 \\
\hline t-statistics Alpha & & 4,3743 & $-1,5247$ \\
\hline t-statistics Beta & & 74,2188 & 46,4256 \\
\hline Error Regression & & 0,0075 & 0,0116 \\
\hline Correlation Returns (\%) & & $81,10 \%$ & $65,51 \%$ \\
\hline R2 & & 0,6577 & 0,4292 \\
\hline Tracking Error (\%) & & $0,7553 \%$ & $1,1676 \%$ \\
\hline
\end{tabular}

In this table, we compare two different momentum strategies with the market proxy using different characteristics. The first column describes the characteristic measured. The second column describes the market characteristics. These are based on a market proxy calculated by averaging all prices of the available assets comprising the Prime Standard (listed in February 2015). The third and fourth columns depict the characteristics of two long-only momentum strategies. The third column is based on a momentum strategy using the upper 10th decile of assets (ranked monthly by the past 12 months performance), whereas the last column is based on a contrarian approach using the lower 10th decile. We list the different calculation methods for the characteristics used in this table in Appendix 1. 
Having reported this setup, we will show in the next section that these characteristics go hand in hand with the business situation of the specific companies allocated to the momentum strategies.

\section{Momentum: An Economic View}

In the following section, we use the assets allocated in the classical momentum strategy (long-only, upper 10th decile) as well as the assets of the contrarian strategy (long-only, lower 10th decile) to analyze the business conditions underlying the momentum effect. We hereby distinguish two different phases. The first phase is the formation period, i.e., the period in which the asset price has momentum (a strong one year performance) that leads to it being allocated to the momentum portfolio. Similarly, we use the same analysis for the contrarian portfolio, in which we analyze weak one-year performance leading to an asset's allocation to the contrarian portfolio. The second analysis is tied to the holding period. This involves analysis of all assets that are allocated for longer than one year.

\subsection{Technicalities}

Before we present the main results of this work, we will describe some technical aspects of the analysis. In subsequent sections, we report the following balance sheet characteristics of the individual companies (notation in EUR):

- Dividend payment per share

- Book value per share

- Cash flow per share

- Earnings before interest and tax (EBIT, per million EUR)

- Earnings per share (per million EUR)

- Total revenue (per million EUR)

- Net income (per million EUR)

For the majority of companies listed in the Prime Standard in Germany, these numbers are officially published in the first two quarters of the year. Since we do not want to rely on any estimates, we use these official values of the balance sheets as reported by the data supplier for our analysis. From a reporting standpoint, we assume that the results from the past year are known to an investor with some delay. Since the publication dates are different for each company, we assume that this information becomes generally available at the second half of the last year. More specifically, we check whether each date used in the analysis lies in the second half of the corresponding year. If so, we use the balance sheet from that year for our analysis. If the date of our analysis falls into the first half of the year, we use the balance sheet from the previous year. This mechanism is an approximation of the more complex reporting schedules found in practice.

We use following rules in our analysis process to account for partially incomplete records in our data set:

1. If a balance sheet record contains at least one entry and the dividend information is missing, then we set that value to 0 (assuming that no dividend was paid).

2. Generally, we assume a one-year period containing approximately 261 trading days. We will analyze the progress of a particular company with respect to the balance sheet by analyzing the differences of all balance sheet values mentioned above over the course of that year.

3. If one of the balance sheets used in this analysis is empty, we remove the entity from further calculations.

4. Finally, we will average the remaining differences, i.e., we use all valid progress reports for a specific company across all periods used in the analysis.

We will demonstrate this by analyzing the market characteristics for 11 years in the next section.

\subsection{Market 2004 - 2014}

As a baseline, we report the market balance sheets during the period of interest (2004 to 2014, i.e., 11 years). Table 2 lists the average values of all balance sheets at the beginning of the period (2004-01-01 using the balance sheets of 2013) and the end of the period (2014-12-31 using the balance sheets of 2014). The construction is as follows:

1. For every company, we analyze the balance sheet progress from 2005 to 2014.

2. For that analysis, we create a yearly progress report by calculating the change in balance sheet values from the prior year to the current year. This comprises of 10 entries referring to the progress report 2004/2005 to 2013/2014. 
3. Finally, we average all yearly progress reports of all companies.

The resulting values represent what we would expect on average if we randomly picked a company and one year time frame. In this process, we had to drop 126 of 2756 calculations due to empty balance sheets.

Table 2. Summary Average Market Progress (2005-2014)

\begin{tabular}{|c|c|c|c|c|c|c|c|c|}
\hline & & $\begin{array}{c}\text { Dividend } \\
\text { per } \\
\text { Share }\end{array}$ & $\begin{array}{c}\text { Book } \\
\text { Value } \\
\text { per } \\
\text { Share }\end{array}$ & $\begin{array}{c}\text { Cashflow } \\
\text { per } \\
\text { Share }\end{array}$ & EBIT & $\begin{array}{c}\text { Earnings } \\
\text { per } \\
\text { Share }\end{array}$ & $\begin{array}{c}\text { Total } \\
\text { Revenue }\end{array}$ & $\begin{array}{c}\text { Net } \\
\text { Income }\end{array}$ \\
\hline $\begin{array}{l}\text { Market } \\
\text { Average }\end{array}$ & Deviation & 0,03 & 0,57 & 0,26 & 39,72 & 0,14 & 283,09 & 31,79 \\
\hline
\end{tabular}

For the market Prime Standard, we list the average balance sheet progress (averaged over all companies and over 10 time period 2004/2005 to 2013/2014 per company where available). The table is comprised of the fundamental data described in section 2.1 .

As shown in Table 2, the overall business condition has improved significantly for the market. We would expect that a random investment in a random year would result in an increased dividend, increased book value per share and an increase of 40 million EUR in EBIT with a total revenue increase of 283 million EUR. The average market price increased by approximately $75 \%$ during the full period.

How does this compare to the assets that are allocated using the two strategies discussed before? We answer this in the next sections by analyzing the formation period and the holding period separately.

\subsection{Formation Phase}

Momentum strategies utilize data on past returns to form a target portfolio. In section I.C, we used a past one-year window to measure the performance of all assets on a monthly basis. In this section, we will analyze the balance sheets with respect to how the business condition changed during the formation period. Similar to in the previous section, we will calculate the average balance sheet values of all assets that will be allocated to the momentum portfolio, recording the balance sheet values at the beginning of a formation period and at the end of that period one year later. This process is repeated for every month in which the momentum strategy re-balances the portfolio. We record only those assets that rank in the highest 10th decile each month (for the classical long-only momentum strategy) during this re-balancing event. We perform the same calculations for the contrarian strategy, in which we use the assets ranked in the lowest 10th decile. As described before, we calculate the deviation during the formation phase only for those assets that have balance sheet records for both dates available. Additionally, we assume a dividend of zero if other balance sheet entries have information available and that particular entry is empty. Table 3 summarizes the averages for the formation phase for all assets allocated to the two separate momentum strategies. For the upper decile, we had to drop 242 of 3751 calculations; for the lower decile, we had to remove 481 entries. 
Table 3. Comparison Market Data vs. Formation of Momentum Strategies

\begin{tabular}{|c|c|c|c|c|c|c|c|c|}
\hline & & $\begin{array}{c}\text { Dividend } \\
\text { per } \\
\text { Share }\end{array}$ & $\begin{array}{c}\text { Book } \\
\text { Value } \\
\text { per } \\
\text { Share }\end{array}$ & $\begin{array}{c}\text { Cashflow } \\
\text { per } \\
\text { Share }\end{array}$ & EBIT & $\begin{array}{c}\text { Earnings } \\
\text { per } \\
\text { Share }\end{array}$ & $\begin{array}{c}\text { Total } \\
\text { Revenue }\end{array}$ & $\begin{array}{c}\text { Net } \\
\text { Income }\end{array}$ \\
\hline $\begin{array}{l}\text { Market } \\
\text { Average }\end{array}$ & Deviation & $\mathbf{0 , 0 3}$ & $\mathbf{0 , 5 7}$ & 0,26 & 39,72 & 0,14 & 283,09 & 31,79 \\
\hline \multirow{3}{*}{$\begin{array}{l}\text { Formation } \\
\text { Momemtum } \\
\text { Best 10\% }\end{array}$} & Begin & 0,35 & 9,27 & 2,00 & 149,58 & 0,16 & $3.571,38$ & 70,37 \\
\hline & End & 0,37 & 9,72 & 2,28 & 181,54 & 0,76 & $3.623,56$ & 97,36 \\
\hline & Deviation & 0,02 & 0,45 & 0,28 & 31,96 & 0,61 & 52,18 & 26,99 \\
\hline \multirow{3}{*}{$\begin{array}{l}\text { Formation } \\
\text { Momemtum } \\
\text { Worst 10\% }\end{array}$} & Begin & 0,31 & 12,96 & 1,10 & 171,74 & $-0,79$ & $2.813,77$ & 77,06 \\
\hline & End & 0,28 & 11,16 & $-0,13$ & 189,81 & $-1,10$ & $2.697,18$ & 82,81 \\
\hline & Deviation & $-0,03$ & $-1,80$ & $-1,23$ & 18,07 & $-0,31$ & $-116,58$ & 5,75 \\
\hline
\end{tabular}

As in Table 2, we list the averaged balance sheet results for the market. We now analyze all assets that are ranked in the highest (or lowest for the contrarian strategy) 10th decile. Every month, we log the balance sheet values at the beginning of the formation period (one year) and the balance sheet values at the end of that period. For all these values, we calculate the deviation during this formation period and calculate the final average, which we sum over all re-balancing events and all assets selected by the strategy. We use the same procedure for the contrarian strategy.

Since the formation period used in this work is one year, we can directly compare the deviation with the market average deviation. As can be verified from this table, the classical momentum strategy involves selecting assets such that the business condition for those assets has improved. In contrast, the contrarian momentum strategy allocates assets in which the average balance sheet values (excluding EBIT and net income) are declining.

For the classical momentum strategy (focusing on the best-performing assets), the improvements from the balance sheet are generally smaller than those in the (averaged) market. Since we are analyzing deviation, we restrict the analysis to the values that are normalized "per share." For these, dividend and book value per share are below the market average. However, cash flow per share is slightly more improved compared to the market, and earnings per share are significantly higher (almost by a factor of five).

Since all balance sheet deviations are positive, we conclude that the classical momentum strategies invest in healthy companies that report better balance sheet values after the formation period on all fronts. In particular, these companies improve earnings better than the average market.

The converse is also true: the contrarian strategy (as a reference) invests in companies, in which the business condition is declining. In particular, cash flow and earnings per share turn significantly negative. Does a momentum strategy capture trends in balance sheets?

We will analyze this in the next section by evaluating assets that are hold for more than one consecutive year.

\subsection{Portfolio (Holding) Phase}

In this section, we analyze the momentum portfolios (classic and contrarian) with respect to the longest held positions. As documented in Berghorn (2015-I), these have a high probability of not corresponding to random walk models. We concentrate on those portfolio positions that are in the momentum portfolio for more than 261 days (roughly 1 year). This totals to 27,534 trading days. The total allocation of the momentum strategies is (31 assets) $\mathrm{x}$ (11 years) $\mathrm{x}$ (261 days per year) $=89,001$ days. Consequently, these assets represent approximately $1 / 3$ of the momentum portfolio. For the upper decile, we removed 5 of 78 entries from the averaging process; 9 of 95 entries were removed from the lower decile. 
Table 4. Comparison Market Data vs. Momentum Strategies

\begin{tabular}{|c|c|c|c|c|c|c|c|c|}
\hline & & $\begin{array}{l}\text { Dividend } \\
\text { per Share }\end{array}$ & $\begin{array}{c}\text { Book Value } \\
\text { per Share }\end{array}$ & $\begin{array}{l}\text { Cashflow } \\
\text { per Share }\end{array}$ & EBIT & $\begin{array}{l}\text { Earnings } \\
\text { per Share }\end{array}$ & $\begin{array}{c}\text { Total } \\
\text { Revenue }\end{array}$ & Net Income \\
\hline Market Average & Deviation & 0,03 & 0,57 & 0,26 & 39,72 & 0,14 & 283,09 & 31,79 \\
\hline \multirow{4}{*}{$\begin{array}{l}\text { Momemtum } \\
\text { Best } 10 \% \\
\text { (Holding >= } 1 \\
\text { Year) }\end{array}$} & Begin & 0,22 & 6,20 & 1,68 & 98,29 & 0,06 & $3.112,27$ & 40,84 \\
\hline & End & 0,39 & 9,41 & 2,10 & 227,33 & 1,91 & $3.502,98$ & 164,75 \\
\hline & Deviation & 0,16 & 3,21 & 0,42 & 129,04 & 1,85 & 390,71 & 123,91 \\
\hline & $\begin{array}{l}\text { Deviation } \\
\text { Weighted }\end{array}$ & 0,06 & 1,19 & 0,20 & 48,66 & 0,66 & 201,11 & 45,70 \\
\hline \multirow{4}{*}{$\begin{array}{l}\text { Momemtum } \\
\text { Worst 10\% } \\
\text { (Holding >= } 1 \\
\text { Year) }\end{array}$} & Begin & 0,23 & 16,08 & $-0,78$ & 124,81 & $-1,17$ & $2.510,65$ & 86,21 \\
\hline & End & 0,13 & 9,23 & $-0,39$ & 86,24 & $-2,30$ & $2.459,14$ & 27,51 \\
\hline & Deviation & $-0,10$ & $-6,85$ & 0,39 & $-38,57$ & $-1,12$ & $-51,51$ & $-58,70$ \\
\hline & $\begin{array}{l}\text { Deviation } \\
\text { Weighted }\end{array}$ & $-0,02$ & $-0,97$ & $\mathbf{0 , 0 7}$ & $-8,91$ & $-0,35$ & 6,22 & $-13,23$ \\
\hline
\end{tabular}

We list the averaged balance sheet progress for the market as a reference. This is compared to the average balance sheet information that is available during the holding period for the classical and contrarian momentum strategies. For the latter, we restrict the analysis to companies that reside inside of the momentum portfolio longer than one year (261 days). The deviation is annualized by dividing this value by the number of days the asset resides in the portfolio multiplied by 261 .

As we can derive from this table, the classical momentum portfolio allocates assets for which, on average, the business condition is improving more than the market average. The dividend increase during the holding period is almost twice as high as what can be expected from a market portfolio. The book value per share is increasing by more than a factor of two. Interestingly, this is not the case for the cash flow per share. The average improvement is below the market average. Regarding the weighted EBIT increase, we report an improvement of approximately $20 \%$ compared with the market improvement. The earnings per share improve more than 4 times higher than the associated market when weighted with the time these are held in the portfolio. The total revenue (weighted), however, is lower compared to the market, and, finally, the net income is $50 \%$ higher than what would be expected from the market.

These results are supported by the analysis of the contrarian portfolio, which shows on average worse business conditions during the residence in the portfolio. All values show inferior results compared with the market; we see even strong declines (on average) during the allocation time period. These positions are held even longer in the contrarian portfolio than in the classical approach (in total 38,573 days out of 89,001 days).

\section{Discussion and Conclusion}

As stated in previous work, the mathematical results indicate strongly the existence of piecewise deterministic trends in market data. These trends are not created by classical random processes such as the random walk (Berghorn 2015-II). Long trends are foundationally important for momentum strategies to work (Berghorn 2015-I). As we have seen from the economic side presented above, these trends are backed by economic processes. Momentum strategies seem to pick up on a significantly better earnings situation.

During allocation, we were able to show that improvements in the balance sheet are correlated with a price increase of the associated asset. In other words, the better business condition is presumably mandating a better price. This transition from one price level or business condition to the next is, according to the results presented above, creating these "more deterministic" trends. In a theoretical world of efficient markets, this should by no means happen. A price reflects all available information and investors anticipate this rationally. As we have shown now from different perspectives, investors fail in that mission, constantly. 
We conclude with a citation from Benoît Mandelbrot in Mandelbrot (2006): "Some economists, when thinking about long memory, are concerned that it undercuts the Efficient Market Hypothesis that prices fully reflect all relevant information; that a random walk is the best metaphor to describe such markets; and that you cannot beat such an unpredictable market. Well the Efficient Market Hypothesis is no more than that, a hypothesis. Many grand theory has died under the onslaught of real data."

\section{Acknowledgements}

We would like to thank Heinz-Otto Peitgen and Marcel van Leeuwen (DPWT Deutsche Wertpapiertreuhand GmbH, Herzogenaurach, Germany) for their ongoing support and the critical discussions. We also would like to thank the Sparkasse Bremen AG for the partnership and for providing an open environment to foster innovation in finance. We would also like to thank Prof. Dr. Matija Denise Mayer-Fiedrich for the continuous support and scientific discussion.

\section{References}

Antoniou, C., Doukas, J., \& Subrahmanyam, A. (2013, Feb.). Cognitive Dissonance, Sentiment, and Momentum, Journal of Financial \& Quantitative Analysis, 48(1), 245-275.

Asness, C. S., Frazzini, A., Israel, R., \& Moskowitz, T J. (2014, May). Fact, Fiction and Momentum Investing. Journal of Portfolio Management, Fall, 40th Anniversary Issue. Fama-Miller Working Paper. http://dx.doi.org/10.2139/ssrn.2435323

Asness, C.S., Moskowitz, T.J., \& Pedersen, L. (2013). Value and momentum everywhere. J. Finance, 68(3), 929-985.

Berghorn, W., \& Otto, S. (2015, June). Mandelbrot Market-Model and Momentum. Retrieved from http://ssrn.com/abstract=2620112

Berghorn, W. (2015). Trend Momentum. Quantitative Finance, 15(2), 261-284 http://dx.doi.org/10.1080/14697688.2014.941912

Choi, S. M., \& Kim, H. (2014, Feb.). Momentum Effect as Part of a Market Equilibrium. Journal of Financial \& Quantitative Analysis, 49(1), 107-130.

Daniel, K. D. (2011, April). Momentum Crashes. Columbia Business School Research Paper No. 11-03. http://dx.doi.org/10.2139/ssrn.1914673

Fama, E.F., \& French, K.R. (2012). Size, value, and momentum in international stock returns. J. Financial Economics, 105, 457-472.

Fama, E.F. (1970). Efficient capital markets: A review of theory and empirical work. J. Finance, 25(2), 383-417.

Jegadeesh, N., \& Titman, S. (1993). Returns to buying winners and sell- ing losers: Implications for stock market efficiency. J. Finance, 48, 65-91.

Kahneman, D., \& Tversky, A. (1979). Prospect theory: An analysis of decision under risk. Econometrica, 47, 263-291.

Lintner, J. (1965). The Valuation of Risk Assets and the Selection of Risky Investments in Stock Portfolios and Capital Budgets. Review of Economics and Statistics, 47(1), 13-37.

Lo, A.W., \& MacKinlay, A.C. (1998). Stock market prices do not follow random walks: Evidence from a simple specification test. Rev. Financ. Stud., 1(1), 41-66.

Mandelbrot B.B., \& Van Ness, J.W. (1968). Fractional Brownian motions, fractional noises and applications. SIAM Review, 10, 422-437

Mandelbrot, B. B., \& Hudson, R. L. (2006). The (Mis)Behaviour of Markets: A Fractal View of Financial Turbulence (annotated ed.). Basic Books.

Markowitz, H. M. (1952). Portfolio Selection. Journal of Finance, 7, S. 77-91.

Moskowitz, T. J., Yoa Hua Ooi, \& Lasse H. Pedersen. (2010, Dec.). Time series momentum. Journal of Financial Economics.

Sharpe, W. (1964). Capital Asset Prices: A Theory of Market Equilibrium under Conditions of Risk. Journal of Finance, 425-442.

Shiller, R. J. (2003). From Efficient Markets Theory to Behavioral Finance. Journal of Economic Perspectives, 17(1), 83-104

Tversky, A., \& Kahneman, D. (1992). Advances in prospect theory: Cumulative representation of uncertainty. Journal of Risk and Uncertainty, 5, 297-323. 


\section{Appendixes}

Appendix 1. Description of Characteristics Measured

Table 1 provides different characteristics of the market proxy (averaged prices) and the momentum strategy. These are listed for the Prime Standard segment for the period 2004 to 2014 (11 years). The momentum strategy uses 31 assets (10th decile) of the underlying market and a 12-month performance-ranking period. In the first two rows, we list the absolute return and the geometric return per year. The next two rows contain the excess return (absolute and geometric return). The "Daily Drift" row denotes the daily drift estimated from the daily log returns using the arithmetic mean. "Daily Volatility" denotes the daily volatility estimated by the standard deviation of the daily log returns. The "Risk-Adjusted Return" entries are calculated by dividing the daily drift by the daily volatility. "Maximal Drawdown" refers to the maximal loss (discrete returns) encountered in the price series. We also apply a linear model to describe the log returns of the classical momentum strategy. Let $y=\boldsymbol{\alpha}+\boldsymbol{\beta} x$. This linear model describes the log returns y of the classical momentum strategy that, according to the market proxy $\log$, returns $\mathrm{x}$. The alpha $(\boldsymbol{\alpha})$ and beta $(\boldsymbol{\beta})$ parameters estimated by the linear regression of this linear model are listed. We also give the coefficient of determination, R2, which is the correlation (listed in the row below) of $\mathrm{x}$ and y squared. Finally, the tracking error between the log returns $\mathrm{x}$ and $\mathrm{y}$ is listed.

\section{Appendix 2. Classic Momentum Strategy Long Only}

In this section, we depict the performance graphs of the classical momentum strategy compared to the market proxy. The result is given in Figure 1 below.

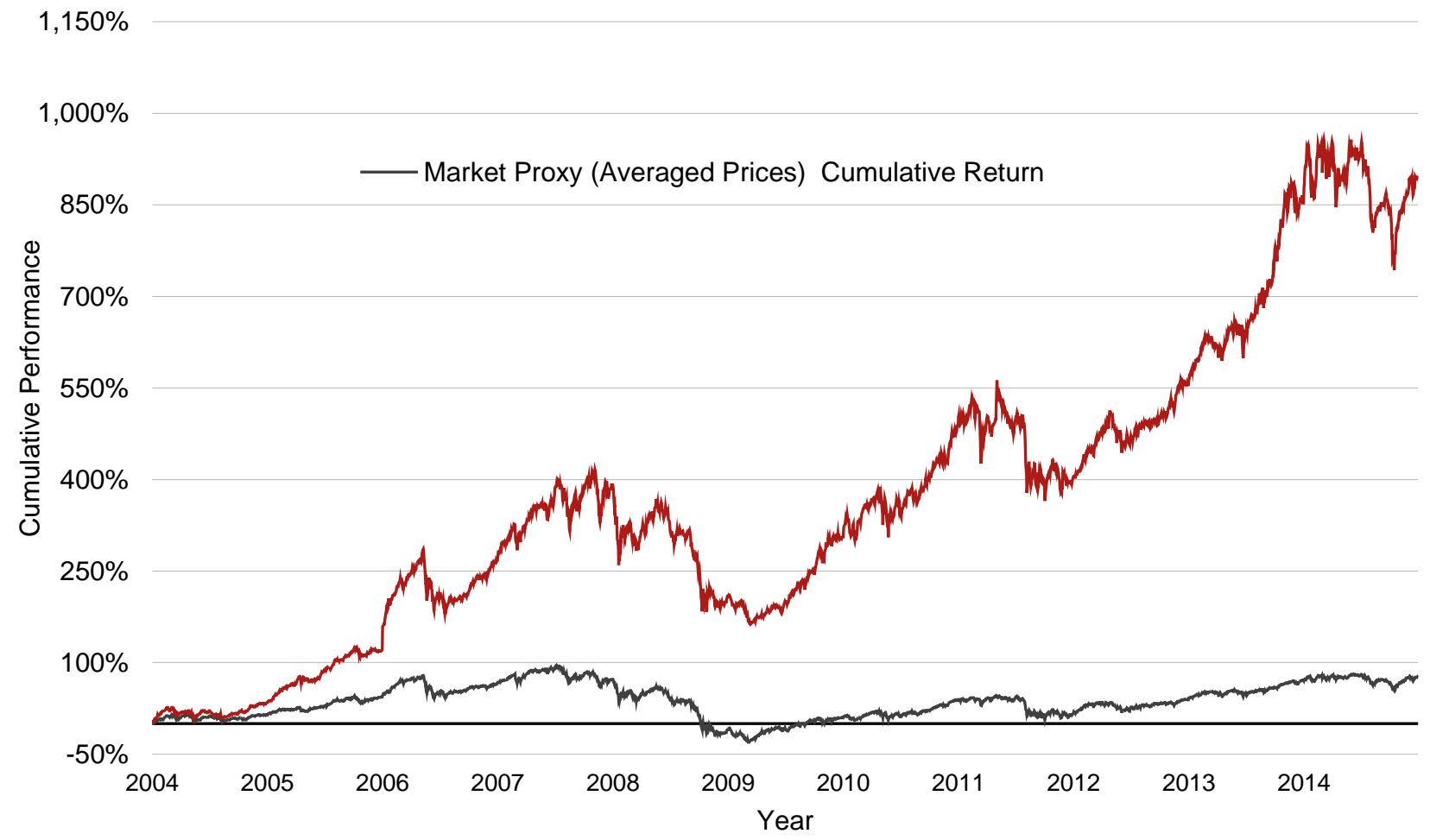

Figure 1. Classic Momentum Strategy (Long-only, 10\% Upper Decile) vs. Market Proxy

For the period 2004 to 2014 (11 years), we depict the cumulative return for the market proxy (using price averaging) with the classical momentum strategy. The momentum strategy uses 31 assets (10th decile) that we rank monthly based on their past 12 months performance. Each month, the top 10\% are invested in the target portfolio. We subtract $0.1 \%$ per month from the simulation to model transaction costs for the momentum strategy. 
As seen from the figure above, this strategy is able to generate significant excess returns over the mid and long term. However, not all phases lead to outperformance. This is depicted in Figure 2 below.

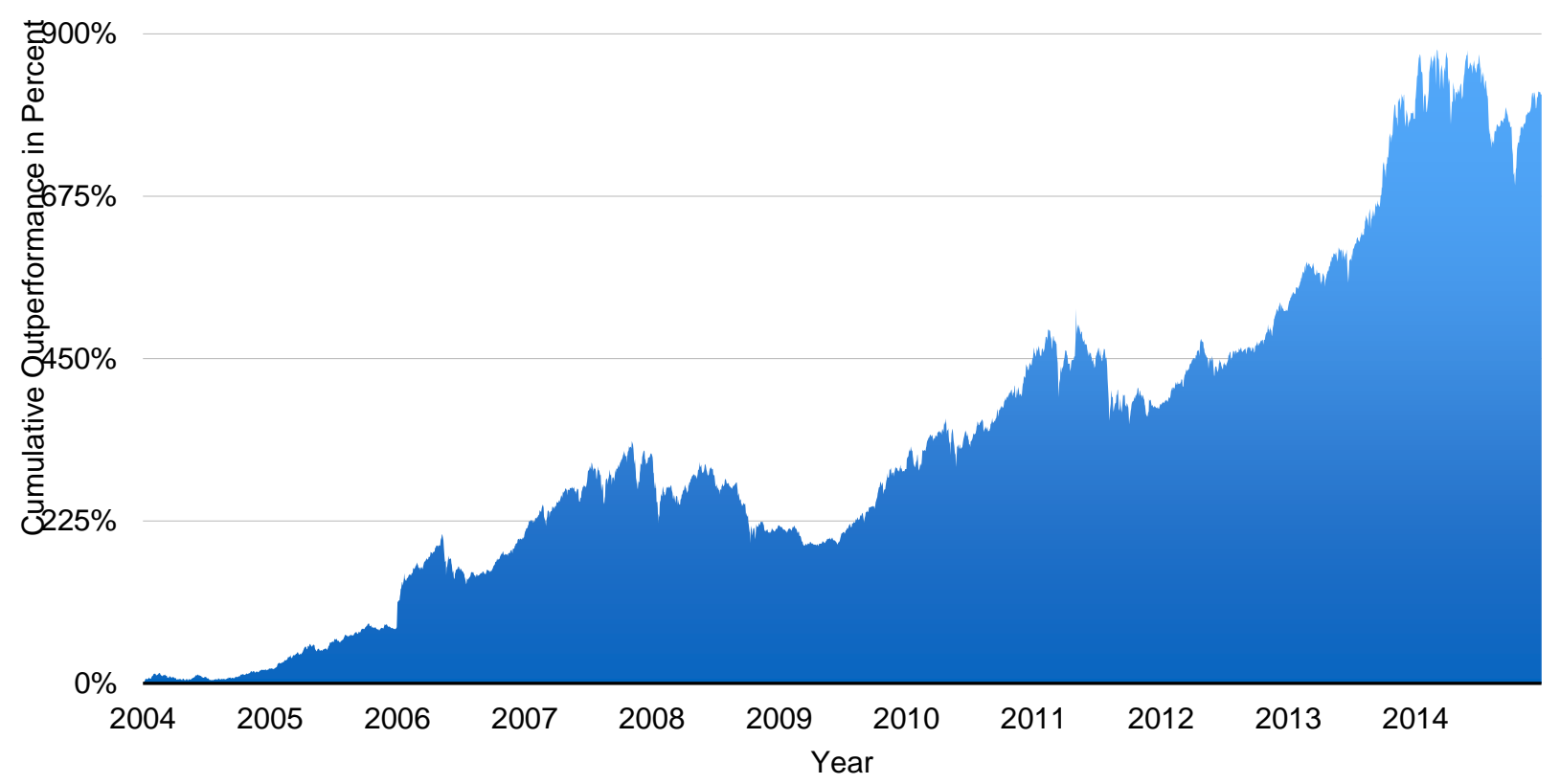

Figure 2. Outperformance: Classic Momentum Strategy (Long-only, 10\% Upper Decile) vs. Market

In this figure, we depict the outperformance of the classical momentum strategy compared to the market proxy. We calculate the outperformance by subtracting the cumulative return of the market proxy from the cumulative return of the momentum strategy.

Momentum strategies have different characteristics in different market phases, as demonstrated above. An inclining market yields outperformance, whereas declining markets, such as during the financial crisis 2008/2009 and the budget crisis in the US 2011, let the momentum strategy underperform. 
Appendix 3. Contrarian Momentum Strategy Long Only

In contrast to the results in section V.2, we use in the following experiments for a contrarian strategy. In particular, we use the worst performers (lowest 10th decile) of the past year in the target portfolio. As known from the literature, the resulting strategy significantly underperforms the market. The result is depicted in Figure 3.

$131 \%$
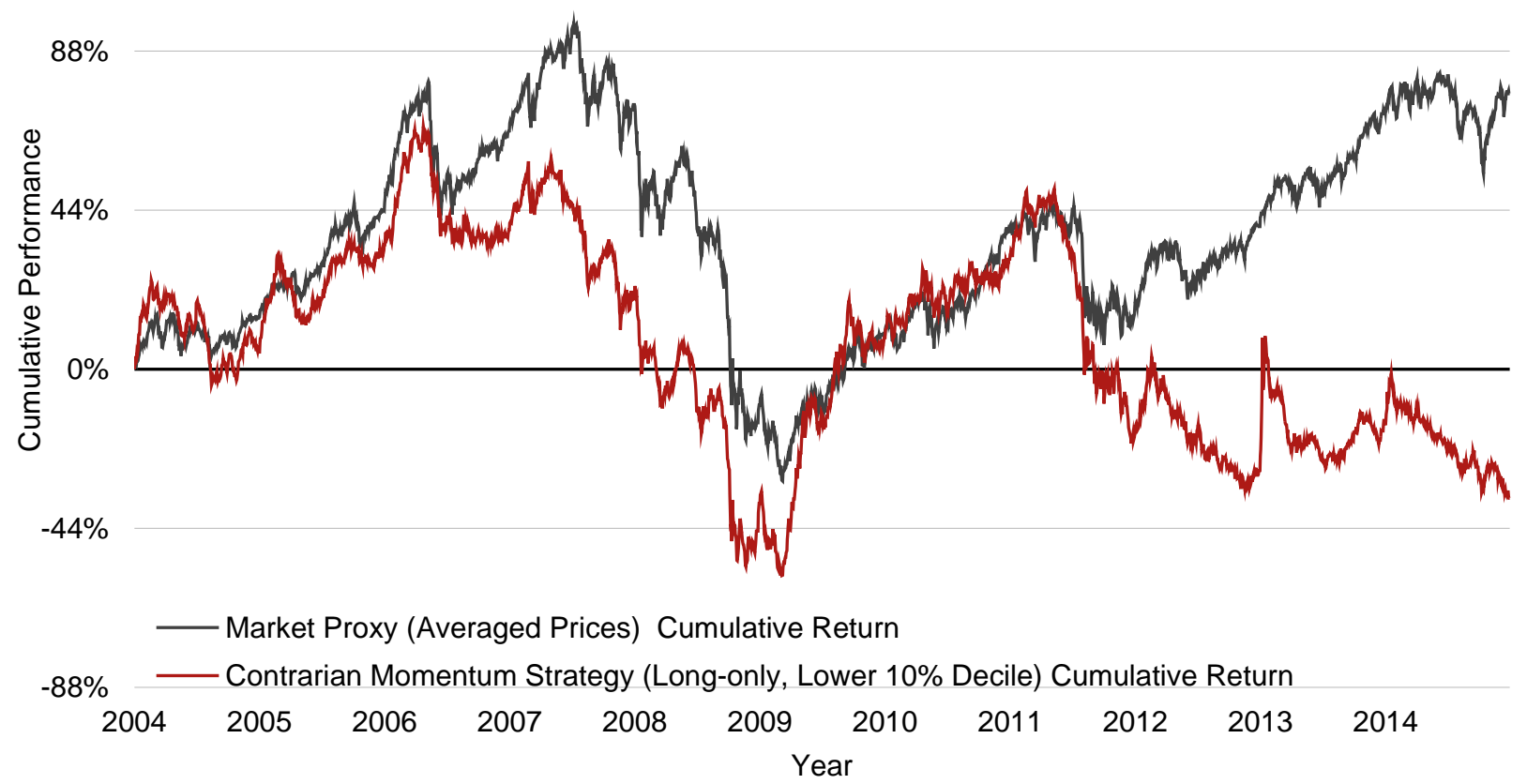

Figure 3. Contrarian Momentum Strategy (Long-only, 10\% Lower Decile) vs. Market Proxy

In contrast to Figure 1, we use the lowest 10th decile for setting up a contrarian, long-only momentum strategy. For the same period 2004 to 2014 (11 years), we depict the cumulative return of this contrarian strategy to the market proxy (using price averaging). The momentum strategy uses 31 assets (10th decile); we rank all assets monthly by their past 12 months“ performance and choose the worst performers for the target portfolio. This simulation also contains transaction costs of $0.1 \%$ per month.

Opposite to the results of the classical (upper 10th decile) momentum strategy, this contrarian approach has the strongest recovery period after the financial crisis 2008/2009. This is shown in Figure 4. 
$38 \%$

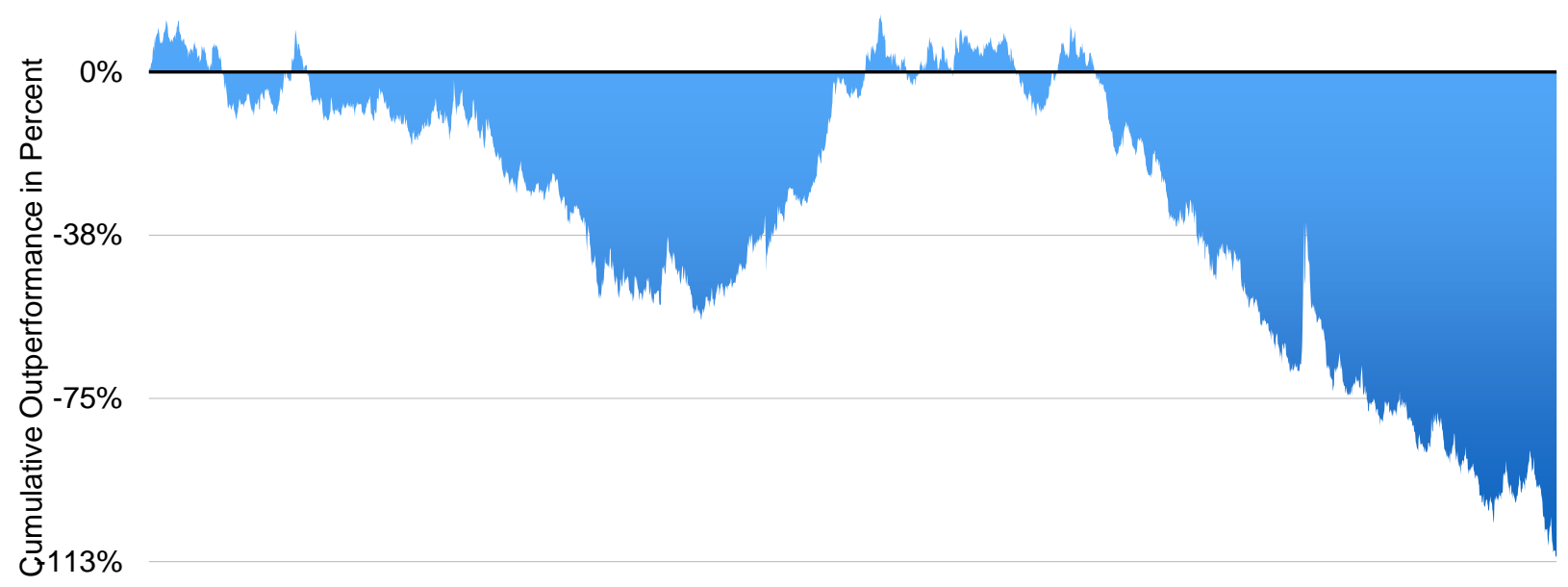

$-150 \%$ 200 2005 2006 2007 2008 20092010 Year

Figure 4. Underperformance: Contrarian Momentum Strategy (Long-only, 10\% Lower Decile) vs. Market

In this figure, we document the underperformance of the contrarian momentum strategy compared to the market proxy. As in Figure 2, we calculate the outperformance by subtracting the cumulative return of the market proxy from the cumulative return of the contrarian strategy.

Similar to the classical momentum strategy, this contrarian approach has different characteristics in different market phases. In declining markets, Figure 4 shows structural underperformance compared to the market proxy. As documented in Daniel (2011), we see that the recovery period 2008/2009 of the market yields higher outperformance. This effect contributes to so-called "momentum crashes" in long-short combinations used in literature. In these scenarios, the worst performers recover faster than the previous best performing assets.

\section{Note}

Note 1. One would also have to define "long-term". 